exon 10 of the beta-glucuronidase gene that creates a novel $5^{1}$ splice site. Hum Mol Genet 1994;4:651-5. Kagie MJ, Kleijer WJ, Huijmans JG, Maaswinkel-Mooy P, Kanhai HH. Beta-glucuronidase deficiency as a cause of fetal hydrops. Am f Med Genet 1992;42:693-5.

7 Nelson A, Pederson L, Frampton B, Sly WS. Mucopolysaccharidosis VII (beta glucuronidase deficiency) presentin as non-immune hydrops fetalis. $\mathcal{F}$ Pediatr 1982;101:574-6.

8 Irani D, Kin HS, El-Hibri H, Dutton RV, Beaudet A, Armstrong D. Postmortem observations on beta glucuronidase deficiency presenting as hydrops fetalis. Ann Neurol 1983;14:486-90.

9 Nelson J, Kenny B, O'Hara D, Harper A, Broadhead D. Foamy changes of placental cells in probable beta glucuronidase deficiency associated with hydrops fetalis. $\mathcal{f}$ Clin Pathol 1993;46:370-1.

10 Chabas A, Guardiola A. Beta-glucuronidase deficiency: identification of an affected fetus with simultaneous sampling of chorionic villus and amniotic fluid. Prenat Diagn 1993;13:429-33.

\title{
Hashimoto's thyroiditis associated with urticaria and angio-oedema: disappearance of cutaneous and mucosal manifestations after thyroidectomy
}

\author{
Antonio Amoroso, Pierluigi Garzia, Cynthia Pasquarelli, Giuseppe Sportelli, \\ Antonella Afeltra
}

University of Rome

"La Sapienza", Rome, Italy:

Department of Clinical

Medicine

A Amoroso

P Garzia

C Pasquarelli

A Afeltra

Institute of Clinical

Surgery II

Giuseppe Sportelli

Correspondence to: Antonella Afeltra MD, Dept Medicina Clinica, Viale dell'Università, 37 - 00185 Rome, Italy.

Accepted for publication 10 December 1996

\begin{abstract}
A 60 year old woman affected by Hashimoto's thyroiditis presented with a history of recurring episodes of urticaria and angio-oedema. Clinical and laboratory evaluation of the patient excluded allergy to external agents, hereditary angiooedema, and occult infections. $A$ pathogenic relation between Hashimoto's thyroiditis and chronic urticaria/angiooedema was suspected. However, treatment with L-thyroxine had no influence on the frequency and severity of the cutaneous and mucosal manifestations, which occurred almost daily and required repeated administration of steroids. The patient therefore underwent total thyroidectomy. Cytometric analysis of intrathyroidal lymphocyte subsets showed unusual abnormalities. Urticaria and angio-oedema completely remitted after surgery; 18 months postoperatively the patient was still asymptomatic.

(f Clin Pathol 1997;50:254-256)
\end{abstract}

Keywords: Hashimoto's thyroiditis; urticaria-angiooedema; intrathyroidal lymphocyte subsets.

Hashimoto's thyroiditis is an organ specific autoimmune disease characterised by an intense thyroid infiltrate of mononuclear cells. It predominantly affects women. Clinical presentation is thyroid enlargement associated with hypothyroidism. Antithyroid antibodies are found in most cases.

Urticaria is a well demarcated skin reaction characterised by oedema involving the superficial portion of the dermis. Lesions are raised and erythematous, and usually pruritic. Angiooedema differs from urticaria in that the oedematous process is located in the deep dermis and subcutaneous or submucosal tissues. Furthermore, lesions are more painful than pruritic. The involvement of the upper respira- tory tract may result in severe and sometimes fatal complications.

Recently an association between idiopathic chronic urticaria and autoimmune thyroiditis has been reported, but its pathogenic mechanisms are still unknown. ${ }^{1-7}$ In this paper we describe the case of a 60 year old woman affected by Hashimoto's thyroiditis associated with cutaneous and mucosal manifestations of urticaria and angio-oedema. The patient underwent total thyroidectomy, and a cytometric analysis of intrathyroidal and peripheral blood lymphocyte subsets was performed. Surgery was followed by a complete remission of urticaria and angio-oedema; 18 months postoperatively the patient was still asymptomatic.

\section{Case report}

A 60 year old woman was admitted to our department in January 1995. Her family history was unremarkable. She had been healthy until July 1993 when thyroid enlargement appeared and raised serum titres of thyroid microsomal and thyroglobulin antibodies were documented; at the same time thyroid function tests showed $\mathrm{FT}_{3}$ and $\mathrm{FT}_{4}$ values within the normal range and high TSH levels. Because of these results, L-thyroxine treatment $(0.1 \mathrm{mg} /$ day) was started.

In March 1994 the patient presented with episodes characterised by urticarial lesions involving the face and trunk, accompanied by swelling of the lips and tongue. Allergy tests were performed, but total IgE (PRIST) and C1-INH values were within the normal range. Routine laboratory analysis revealed only an increase of erythrocyte sedimentation rate (ESR) of $40 \mathrm{~mm} / \mathrm{h}$. During the following months attacks of urticaria and angio-oedema recurred, with progressively increasing frequency and severity; on several occasions, airway involvement caused respiratory obstruction. Attacks were treated with steroids (betamethasone, $4 \mathrm{mg}$ intravenously). Continuous 
oral treatment with betamethasone $(0.5 \mathrm{mg} /$ day) was also given but was ineffective in preventing recurrences.

On admission the patient was in good general conditions but overweight (body mass index $28.7 \mathrm{~kg} / \mathrm{m}^{2}$ ). Urticarial lesions were present on the skin of face and trunk. In addition the patient showed thyroid enlargement of parenchymatous consistency. Routine laboratory analysis showed the following results: haemoglobin $125 \mathrm{~g} / \mathrm{l}$; leucocytes $9 \times 10^{9} / 1$ with a normal differential cell count; platelets $378 \times 10^{9} / 1$; ESR $52 \mathrm{~mm} / \mathrm{h}$; total proteins $62 \mathrm{~g} / 1$. Testing for hepatitis B surface antigen was negative. Total IgE was within the normal range. Skin tests for inhalants were negative and the determinations of specific IgE for a panel of food allergens showed no abnormalities. C3, C4, and C1-INH were within normal limits. Antinuclear antibody and rheumatoid factor assays were negative. Thyroid function tests were within the normal range. The serum titres of thyroglobulin and thyroid microsomal antibodies were 1:40 and $>1: 25600$, respectively. Thyroid echography showed a diffusely hypoechoic gland with an irregular surface, suggesting a chronic thyroiditic process. Subsequent thyroid scan $\left(\mathrm{Tc}^{99 \mathrm{~m}}\right)$ and radioactive iodine uptake showed markedly reduced uptake values; the thyroid was located lower than normal and was significantly enlarged, with marked prevalence of the right lobe; fixation of $\mathrm{Tc}^{99 \mathrm{~m}}$ was globally decreased; intraparenchymal isotope distribution appeared diffusely irregular. Ear, nose and throat, oral-dental, and gynaecological examinations showed no abnormalities. Sinus and dental radiographs were negative. Stool tests for ova and parasites were also negative. A biopsy specimen of skin affected by wheal and flare lesions revealed a histology consistent with urticaria.

During her hospital admission the episodes of urticaria and angio-oedema occurred almost daily, so that repeated administrations of steroids were required. The angio-oedema was not life threatening but, together with the urticaria, it caused a great discomfort. Concentrations of thyroid microsomal antibodies were persistently raised. Treatment of the thyroiditis with L-thyroxine had no effect on the frequency and severity of the attacks of urticaria and angio-oedema. For these reasons we decided on total thyroidectomy, which was performed in March 1995. Histological examination of five different specimens of thyroid tissue showed the typical changes of Hashimoto's thyroiditis. No signs of thyroid lymphoma were found.

Analysis of intrathyroidal and peripheral blood lymphocytes was performed on a FACSCAN cytometer; all the values were obtained after subtracting background staining produced by isotype matched mouse monoclonal antibodies not reactive with human leucocytes. The percentage of $\mathrm{B}$ cells $\left(\mathrm{CD} 19^{+}\right)$was higher in the thyroid than in the peripheral blood $(22 \% v 14 \%)$, while the proportions of $\mathrm{T}$ $\left(\mathrm{CD}^{+}\right)$and $\mathrm{NK}\left(\mathrm{CD} 16^{+}\right)$cells were lower in the gland than in the peripheral blood $(40 \% v$ $72 \%$ and $4 \% v 20 \%$, respectively). Intrathyroi-
Table 1 Lymphocyte characterisation

\begin{tabular}{|c|c|c|}
\hline & Peripheral blood \%* & Thyroid \% \\
\hline $\mathrm{CD}^{+}{ }^{+}$ & $72(65-77)$ & 40 \\
\hline $\mathrm{CD}^{+}{ }^{+}$HLA-DR ${ }^{+} \dagger$ & $10(1.5-7.9)$ & 33 \\
\hline $\mathrm{CD}^{+} \mathrm{CD}^{+} 9^{+} \dagger$ & $4.5(0.8-3.2)$ & 20 \\
\hline $\mathrm{CD}^{+} \mathrm{CD}^{2} 5^{+} \dagger$ & $3(0.0-3.1)$ & 4.7 \\
\hline $\mathrm{CD}^{+}{ }^{+} \mathrm{TCR}_{\gamma} \delta^{+} \dagger$ & $1.7(2.3-8.3)$ & 16 \\
\hline $\mathrm{CD}^{+}$ & $52(39-51)$ & 27 \\
\hline $\mathrm{CD}^{+}{ }^{+} \mathrm{CD} 45 \mathrm{RA}^{+} \ddagger$ & $62(45.5-58.5)$ & 50 \\
\hline $\mathrm{CD}^{+}$ & $18(15-31)$ & 13.5 \\
\hline $\mathrm{CD}^{+} \mathrm{CD} 11 \mathrm{~b}^{+} \ddagger$ & $22(35.5-51.5)$ & 11 \\
\hline $\mathrm{CD} 16^{+}$ & $20(8-22)$ & 4 \\
\hline $\mathrm{CD} 19^{+}$ & $14(7-15)$ & 22 \\
\hline $\mathrm{CD} 9^{+} \mathrm{CD}^{+} \ddagger$ & $28(12.5-26.5)$ & 10 \\
\hline
\end{tabular}

Peripheral blood (PB) leucocytes, $9 \times 10^{9} / 1$; PB lymphocytes, $1.89 \times 10^{9} / 1$.

*Normal ranges in parentheses.

+Values expressed as a percentage of total $\mathrm{CD}^{+}$cells.

$\ddagger$ Values expressed as a percentage of corresponding total subsets (CD4, CD8 and CD19, respectively).

dal B cell subsets were mostly represented by $\mathrm{CD}^{1} 9^{+} \mathrm{CD}^{-}$cells. Thyroid $\mathrm{T}$ cells were in a state of marked activation, as shown by a higher expression of HLA-DR antigen, CD69 (early activation antigen), and CD25 (IL-2 receptor) than in peripheral blood lymphocytes. Intrathyroidal $\mathrm{CD}^{+} \mathrm{T}$ cells predominantly showed the cytotoxic lymphocyte phenotype $\left(\mathrm{CD}^{+} \mathrm{CD} 1 \mathrm{bb}^{-}\right)$. We also found a marked proportional increase of $\mathrm{T}$ cells bearing a $\gamma \delta$ receptor $\left(\mathrm{CD}^{+} \mathrm{TCR} \gamma \delta^{+}\right)$in the thyroid, in comparison to peripheral blood ( $16 \% v 1.7 \%)$ (table 1).

There was complete remission of cutaneous and mucosal symptoms during the days following surgery. Three months postoperatively the serum titre of thyroid microsomal antibodies was 1:6400 and no thyroglobulin antibodies were detected. At an 18 month postoperative follow up the patient, who was receiving L-thyroxine as a replacement therapy, was in a state of metabolic compensation, with no detectable thyroid microsomal and thyroglobulin antibodies and no further episodes of urticaria and angio-oedema.

\section{Discussion}

Hashimoto's thyroiditis is an autoimmune disease characterised by a functional defect of thyroid specific suppressor T lymphocytes. ${ }^{8}$ As a consequence, $\mathrm{T}$ helper cells are autoreactive and cooperate with $B$ cells to produce antithyroid antibodies. Whether tissue damage results from cell mediated immunity, humoral mechanisms, or both is still uncertain. However, the analysis of intrathyroidal lymphocytes may help to define better the immune imbalance underlying this disease.

Our results, showing important modifications in the percentage of lymphocyte subsets, largely agree with those obtained by Iwatany et $a l .9$ According to these investigators the presence of a high proportion of cytotoxic $T$ cells is distinctive of Hashimoto's thyroiditis, such lymphocytes being the main effectors of thyroid epithelial cell necrosis; on the other hand the percentage of $\mathrm{CD}^{-} \mathrm{B}$ cells seems to be correlated with serum concentrations of thyroid microsomal antibodies. ${ }^{9}$

Interestingly, we found an increased expression of activation markers on $\mathrm{CD}^{+}$cells in the thyroid and a very high percentage of $\gamma \delta \mathrm{T}$ 
lymphocytes. Teng et al have also reported an increase of such cells in Hashimoto's thyroiditis. ${ }^{10} \gamma \delta \mathrm{T}$ lymphocytes represent a minority of peripheral blood $\mathrm{T}$ cells; they are predominantly CD4 and CD8 negative, and show non-MHC restricted cytotoxic activity. ${ }^{112}$ In Hashimoto's thyroiditis $\gamma \delta \mathrm{T}$ lymphocytes probably kill thyroid epithelial cells non-specifically.

In the case we report here, Hashimoto's thyroiditis was associated with recurring episodes of urticaria and angio-oedema. Clinically, urticaria and angio-oedema can be divided into acute and chronic varieties, depending on the length of time since onset (less than or more than six weeks). While the aetiology of acute urticaria and angio-oedema can be identified in most patients, chronic forms are labelled as idiopathic in about $80 \%$ of cases or more. ${ }^{6}$ Indeed, patients affected by chronic urticaria are often properly though unsuccessfully investigated, which applies in our case.

In 1983 Leznoff $e t$ al reported the association of chronic urticaria, often accompanied by angio-oedema, with raised titres of thyroid microsomal antibodies. ${ }^{1}$ In 1989 Leznoff then reported the results of a survey of 624 patients affected by idiopathic chronic urticaria and angio-oedema. Ninety of these had high titres of thyroid microsomal antibodies and 44 presented other clinical and laboratory findings suggestive of autoimmune thyroiditis. This was confirmed by biopsy or needle aspirate in some patients with goitre. $^{3}$

Since then the association between chronic urticaria and autoimmune thyroiditis has been reported by other investigators. ${ }^{24-7}$ However, its significance has not yet been established.

It is well known that in both urticaria and angio-oedema a central role is played by mast cells which-in response to immunological or non-immunological stimuli-release preformed (histamine, neutral proteases, ECF-A) and newly generated mediators $\left(\mathrm{PGD}_{2}, \mathrm{LTC}_{4}\right.$, $\left.\mathrm{D}_{4}, \mathrm{E}_{4}\right)$. Leznoff and Sussman hypothesised that idiopathic chronic urticaria is due, at least in some cases, to autoimmune pathogenic mechanisms, and the association with thyroiditis simply expresses an individual predisposition to autoimmune diseases. ${ }^{3}$

In the case reported here, we did not rule out the possibility that the urticaria and angiooedema depended on autoimmune chronic thyroid inflammation. However, in contrast to other investigators' reports, ${ }^{313}$ treatment of the autoimmune thyroid disease with L-thyroxine had no effect on the cutaneous and mucosal manifestations. Since there was a raised titre of thyroid microsomal antibodies, the thyroiditis could also have been managed with immunosuppressive agents, but this would have involved an unacceptable likelihood of adverse effects. For these reasons we attempted an alternative therapeutic approach, that is surgery-not least because the patient had reduced thyroid function and needed replacement hormone therapy in any case. Urticaria and angio-oedema, which had begun to recur more and more frequently, showed dramatic remission after surgery, and the patient currently remains symptom-free, with no need for any kind of antiallergy treatment.

Three months postoperatively, the serum titre of thyroid microsomal antibodies was $1: 6400$ and there were no detectable thyroglobulin antibodies; at the time of writing (after 18 months' follow up), the thyroid microsomal antibodies were no longer detectable. Thus there was no temporal association between the decline in thyroid autoantibodies and remission of cutaneous and mucosal symptoms; it has already been suggested that thyroid autoantibody levels do not correlate with disease activity. ${ }^{13}$

Recently, a case of Graves' disease has been described $^{7}$ in which urticaria and angiooedema improved after radioactive iodine treatment and subsequent L-thyroxine replacement therapy. However, we have not found previous reports of surgically treated autoimmune thyroiditis in patients with urticaria or angio-oedema.

Though the role of an underlying autoimmune diathesis has been emphasised, the link between Hashimoto's thyroiditis and chronic urticaria remains unclear. In the case described here, the disappearance of cutaneous and mucosal manifestations after thyroidectomy, along with the documented alterations in intrathyroidal lymphocyte subsets, strongly supports the hypothesis of a close pathogenic relation between these two diseases.

1 Leznoff A, Josse RG, Denburg J, Dolovich J. Association of chronic urticaria and angioedema with thyroid autoimmunity. Arch Dermatol 1983;119:636-40.

2 Lanigan SW, Short P, Moult P. The association of chronic urticaria and thyroid autoimmunity. Clin Exp Dermatol 1987;12:335-8.

3 Leznoff A, Sussman GL. Syndrome of idiopathic chronic urticaria and angioedema with thyroid autoimmunity: a
study of 90 patients. $₹$ Allergy Clin Immunol $1989 ; 84: 66-71$.

4 Cooper KD. Urticaria and angioedema: diagnosis and Cooper KD. Urticaria and angioedema: diagno

5 Sibbald RG, Cheema AS, Lozinski A, Tarlo S. Chronic urticaria: evaluation of the role of physical, immunologic and other contributory factors. Int $\mathcal{f}$ Dermatol 1991;30: $381-6$.

6 Huston DP, Bressler RB. Urticaria and angioedema. Med Clin North Am 1992;76:805-40.

7 Altus P, Blandon R, Wallach PM, Flannery MT. Case report: the spectrum of autoimmune thyroid disease with urticaria. Am $\mathcal{Y}$ Med Sci 1993;306:379-80.

8 Yoshikawa N, Morita T, Resetkova E, Arreanza G, Carayon P, Volpé R. Reduced activation of suppressor T lymphocytes by specific antigens in autoimmune thyroid disease. $\mathcal{F}$ Endocrinol Invest 1992;15:609-17.

9 Iwatani Y, Hidaka Y, Matsuzuka F, Kuma K, Amino N. Intrathyroidal lymphocyte subsets, including unusual $\mathrm{CD} 4^{+} \mathrm{CD} 8^{+}$cells and CD $3^{10} \mathrm{TCR} \alpha \beta^{\text {lol- }} \mathrm{CD} 4^{-} \mathrm{CD} 8-$ cells, in autoimmune thyroid disease. Clin Exp Immunol 1993;93: $430-6$.

10 Teng WP, Cohen SB, Posnett DN, Weetman AP. T cell receptor phenotypes in autoimmune thyroid disease. $f$ Endocrinol Invest 1990;13:339-42.

11 Brenner MB, Strominger JL, Krangel MS. The $\gamma \delta \mathrm{T}$ cell receptor. Adv Immunol 1988;43:133-92.

12 Haas W, Pereira P, Tonegawa S. $\gamma \delta$ Cells. Annu Rev Immunol 1993;11:637-86.

13 Rumbyrt JS, Katz JL, Schocket AL. Resolution of chronic urticaria in patients with thyroid autoimmunity. $f$ Allergy Clin Immunol 1995;96:901-5. 